\section{BMJ Open \\ Respiratory \\ Research}

\title{
Precise navigation surgery of tumours in the lung in mouse models enabled by in situ fluorescence labelling with a killer-reporter adenovirus
}

Shuya Yano, ${ }^{1,2,3}$ Yong Zhang, ${ }^{1}$ Shinji Miwa, ${ }^{1,2}$ Hiroyuki Kishimoto, ${ }^{3}$ Yasuo Urata, ${ }^{4}$ Michael Bouvet, ${ }^{2}$ Shunsuke Kagawa, ${ }^{3}$ Toshiyoshi Fujiwara, ${ }^{3}$ Robert M Hoffman ${ }^{1,2}$

To cite: Yano S, Zhang Y, Miwa $S$, et al. Precise navigation surgery of tumours in the lung in mouse models enabled by in situ fluorescence labelling with a killer-reporter adenovirus. BMJ Open Resp Res 2015;2:e000096. doi:10.1136/bmjresp-2015000096

- Additional material is available. To view please visit the journal (http://dx.doi.org/ 10.1136/bmjresp-2015000096)

Received 10 June 2015 Revised 8 July 2015 Accepted 10 July 2015

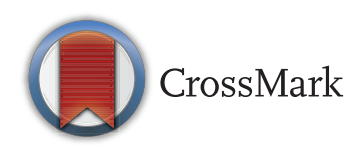

${ }^{1}$ AntiCancer, Inc., San Diego, California, USA

${ }^{2}$ Department of Surgery, University of California, San Diego, California, USA

${ }^{3}$ Department of

Gastroenterological Surgery, Okayama University Graduate School of Medicine, Dentistry and Pharmaceutical Sciences, Okayama, Japan

${ }^{4}$ Oncolys BioPharm Inc.,

Tokyo, Japan

Correspondence to Dr Robert M Hoffman; all@anticancer.com

\section{ABSTRACT}

Background: Current methods of image-guided surgery of tumours of the lung mostly rely on CT. A sensitive procedure of selective tumour fluorescence labelling would allow simple and high-resolution visualisation of the tumour for precise surgical navigation.

Methods: Human lung cancer cell lines $\mathrm{H} 460$ and A549 were genetically transformed to express red fluorescent protein (RFP). Tumours were grown subcutaneously for each cell line and harvested and minced for surgical orthotopic implantation on the left lung of nude mice. Tumour growth was measured by fluorescence imaging. After the tumours reached $5 \mathrm{~mm}$ in diameter, they were injected under fluorescence guidance with the telomerase-dependent green fluorescent protein (GFP)-containing adenovirus, OBP-401. Viral labelling of the lung tumours with GFP precisely colocalised with tumour RFP expression. Three days after administration of OBP-401, fluorescence-guided surgery (FGS) was performed.

Results: FGS of tumours in the lung was enabled by labelling with a telomerase-dependent adenovirus containing the GFP gene. Tumours in the lung were selectively and brightly labelled. FGS enabled complete lung tumour resection with no residual fluorescent tumour.

Conclusions: FGS of tumours in the lung is feasible and more effective than bright-light surgery.

\section{INTRODUCTION}

Fluorescence-guided surgery (FGS) of cancer is an area of intense current interest. Our laboratory used orthotopic mouse models of cancer to develop FGS using both fluorescent cancer-specific antibodies ${ }^{1-9}$ and a green fluorescent protein (GFP)-containing telomerase-dependent adenovirus (OVP-401) to label tumours. ${ }^{10-15}$

In a recent study from our laboratory, telomerase-dependent adenovirus OBP-401 infection brightly and selectively labelled glioblastoma multiforme (GBM) with GFP for FGS in orthotopic nude mouse models. OBP-401-based FGS enabled curative resection of GBM without recurrence for at least 150 days, compared with less than 30 days with bright-light surgery (BLS). ${ }^{14}$

In another recent study from our laboratory, human fibrosarcoma HT-1080 expressing red fluorescent protein (RFP) was implanted orthotopically in the quadriceps femoris muscle of nude mice. The tumourbearing mice were injected with high-dose and low-dose adenovirus OBP-401 which labelled the tumour with GFP. FGS or BLS was then performed. OBP-401 could label the fibrosarcoma with GFP in situ, concordant with RFP. OBP-401-based FGS resulted in superior resection of the fibrosarcoma in this orthotopic model, compared with BLS. High-dose administration of OBP-401 enabled FGS without residual fibrosarcoma cells or local or metastatic recurrence, due to its dual effect of cancer-cell labelling with GFP and killing. High-dose OBP-401-based FGS improved disease-free survival as well as preserved muscle function compared with BLS. $^{15}$

In a patient-derived orthotopic xenograft (PDOX) model of pancreatic cancer, OBP-401 was used to label the cancer cells with GFP. The PDOX was previously grown in an RFP transgenic mouse that stably labelled the PDOX stroma cells bright red. The colour-coded PDOX model, with GFPexpressing cancer cells and RFP-expressing stroma, enabled FGS to completely resect the pancreatic tumours including stroma. Dualcoloured FGS significantly prevented local recurrence, which BLS or single-colour FGS did not. ${ }^{13}$

We previously developed a metastatic lung cancer model that utilises histologically-intact 
lung tumour tissue implanted into the left lung by a thoracotomy procedure. This method resulted in extensive local growth in nude and severe combined immunodeficiency mice, as well as development of regional and distant metastases. ${ }^{16}$

Lung cancer surgery has been improved by CT and other imaging technology. ${ }^{17-23}$ In the present study, we demonstrate that OBP-401 labels orthotopic lung cancer in situ in nude mice, enabling highly effective FGS of the lung tumour. The simplicity and effectiveness of the FGS technology described in the present report suggests important improvements over current methods of image-assisted lung cancer surgery.

Figure 1 OBP-401 labels lung cancer cells in Gelfoam histoculture. Human lung cancer A549 cells expressing RFP $\left(2 \times 10^{6}[A, B]\right.$ or $\left.2 \times 10^{7}[C, D]\right)$ were seeded in Gelfoam histoculture. OBP-401 was added at $1 \times 10^{8}$ PFU $48 \mathrm{~h}$ after cell seeding. Images were acquired with the OV100 Small Animal Imaging System (Olympus, Tokyo, Japan) $(A, C)$ or with a confocal laser scanning microscope FV1000 (Olympus). (B and D) OBP-401 labelled lung cancer cells in three-dimensional Gelfoam histoculture. Representative images of A549-RFP lung cancer cells before and after infection of OBP-401 at $1 \times 10^{8} \mathrm{PFU}$.
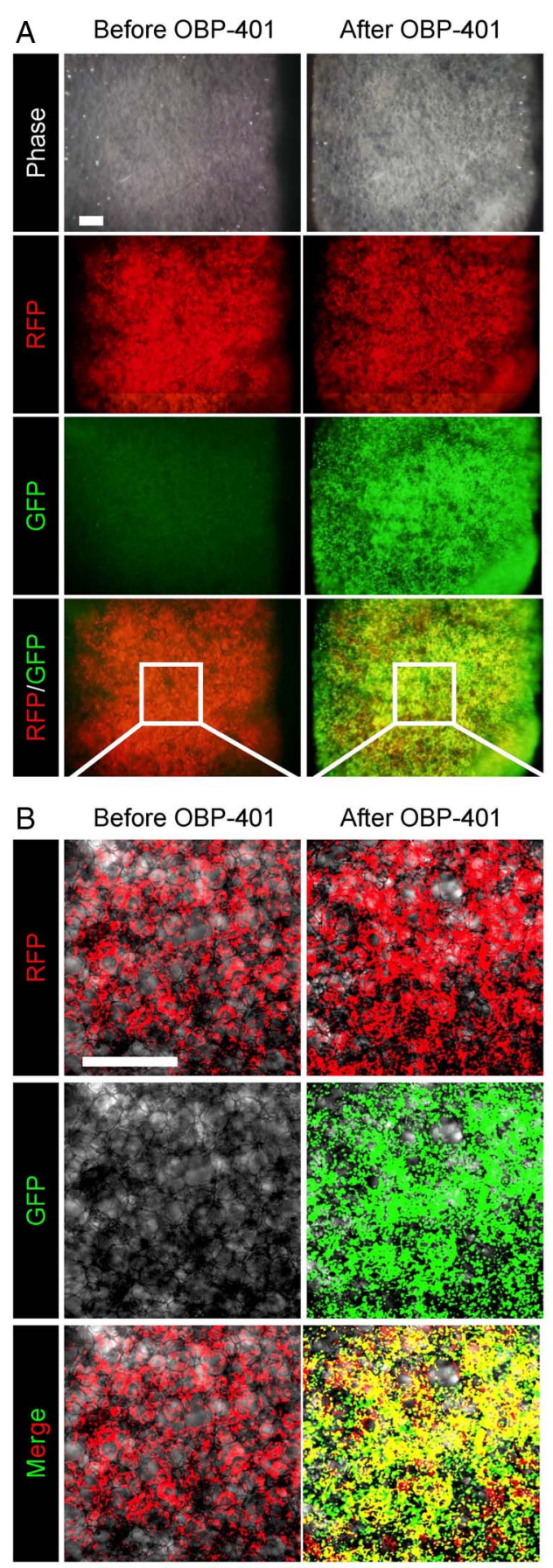

\section{MATERIALS AND METHODS}

\section{GFP-expressing telomerase-specific adenovirus}

The recombinant GFP-expressing, cancer-specific adenovirus OBP-401 contains the promoter element of the human telomerase reverse transcriptase ( $h T E R T)$ gene which drives the expression of E1A and E1B genes linked to an internal ribosome entry site for selective replication only in cancer cells. The GFP gene is driven by the cytomegalovirus promoter, which was constructed as previously described. ${ }^{24}$

\section{Cell culture}

Human lung cancer cell lines A549 and H460 were maintained and cultured in RPMI-1640 medium
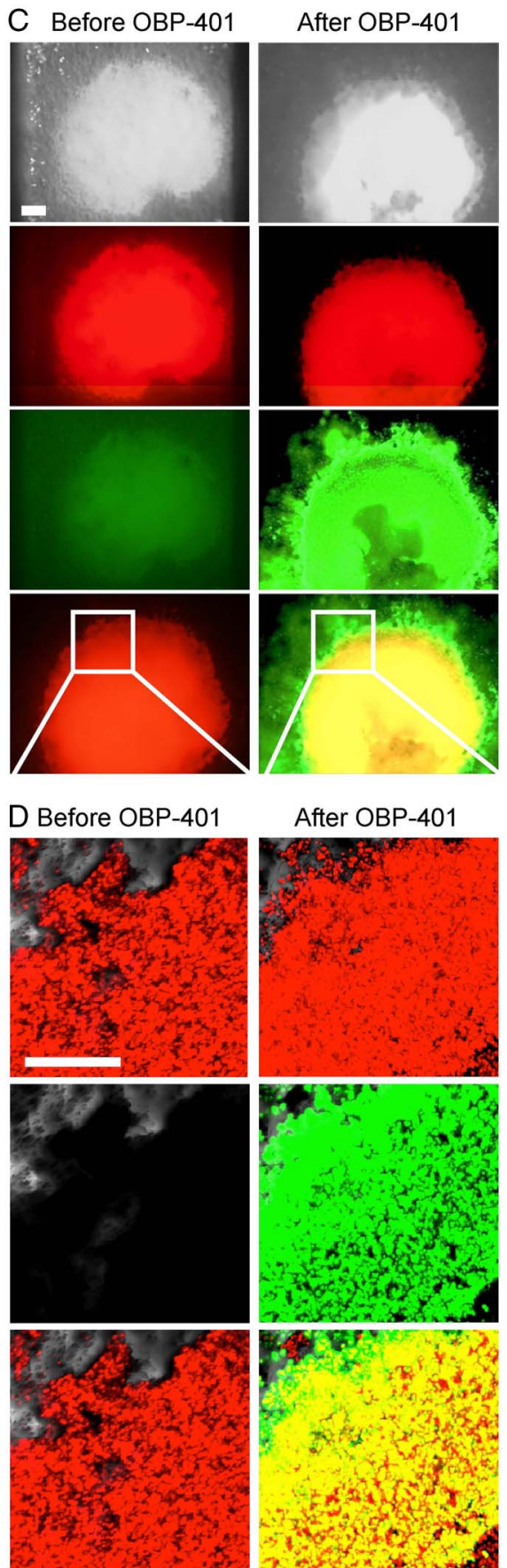
with $10 \%$ fetal bovine serum and $5 \%$ penicillin/ streptomycin.

\section{Mouse experiments}

Athymic nude mice (AntiCancer Inc, San Diego, California, USA) were kept in a barrier facility under HEPA filtration. Mice were fed with autoclaved laboratory rodent diet (Tecklad LM-485, Western Research Products). All animal studies were conducted in accordance with the principles and procedures outlined in the National Institutes of Health Guide for the Care and Use of Laboratory Animals under Assurance Number A3873-01.

\section{Establishment of solitary lung-tumour mouse model}

Cancer cells $\left(2 \times 10^{6}\right)$ were injected initially into the flank of nude mice to obtain stock tumour. When the subcutaneous tumour reached approximately $10 \mathrm{~mm}$ diameter, it was harvested and cut into $1 \mathrm{~mm}$ fragments. For direct implantation, a piece of tumour was sutured with 8-0 nylon on the left lower lobe of the lung ${ }^{162526}$ of mice under isoflurane anaesthesia.

\section{In vitro or ex vivo imaging}

Images of OBP-401 labelling of cancer cells in vitro or tumour ex vivo were acquired with a confocal laser-scanning microscope (FV1000; Olympus Corp, Tokyo, Japan). ${ }^{27}$

\section{In vivo whole body/whole tumour imaging}

For whole-body or whole-tumour imaging, an OV100 Small Animal Imaging System (Olympus Corp) was used. $^{28}$

\section{OBP-401-based FGS}

FGS was performed under anaesthesia using subcutaneous administration of a ketamine mixture $(10 \mu \mathrm{L}$ ketamine $\mathrm{HCl}, 7.6 \mu \mathrm{L}$ xylazine, $2.4 \mu \mathrm{L}$ acepromazine maleate and $10 \mu \mathrm{L}$ PBS). After thoracotomy, the OBP-401-labelled tumour was imaged with the OV100 and resected. After resection of the tumour, the thoracic wall of the mice was closed with $6-0$ sutures

\section{RESULTS}

We first confirmed that OBP-401 selectively labelled lung cancer cells with GFP in monolayer culture. Lung cancer cell lines A549 and H460 expressing RFP were additionally labelled with OBP-401-GFP. The cells became yellow in a dose-dependent manner after infection with OBP-401 due to expression of GFP as well as RFP (see online supplementary figure S1). GFP expression reached a plateau at 3 days after infection in vitro of A549-RFP and H460-RFP cells (see online supplementary figure S2).

Next, we demonstrated that OBP-401 labelled lung cancer cells in three-dimensional Gelfoam histoculture, where lung cancer cells formed tumour-like structures

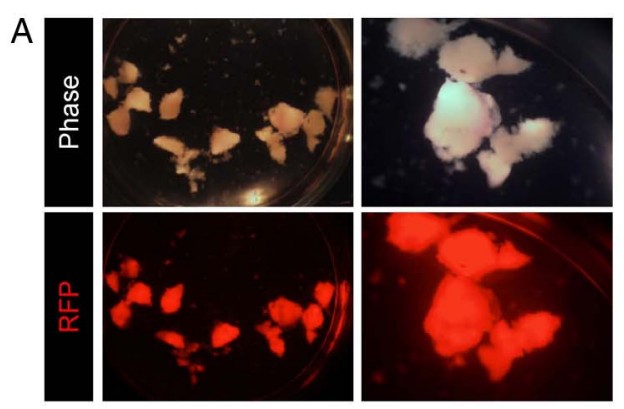

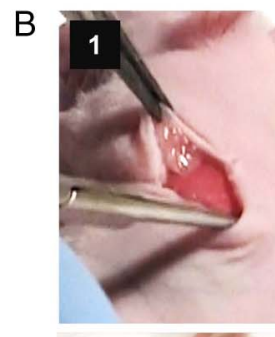
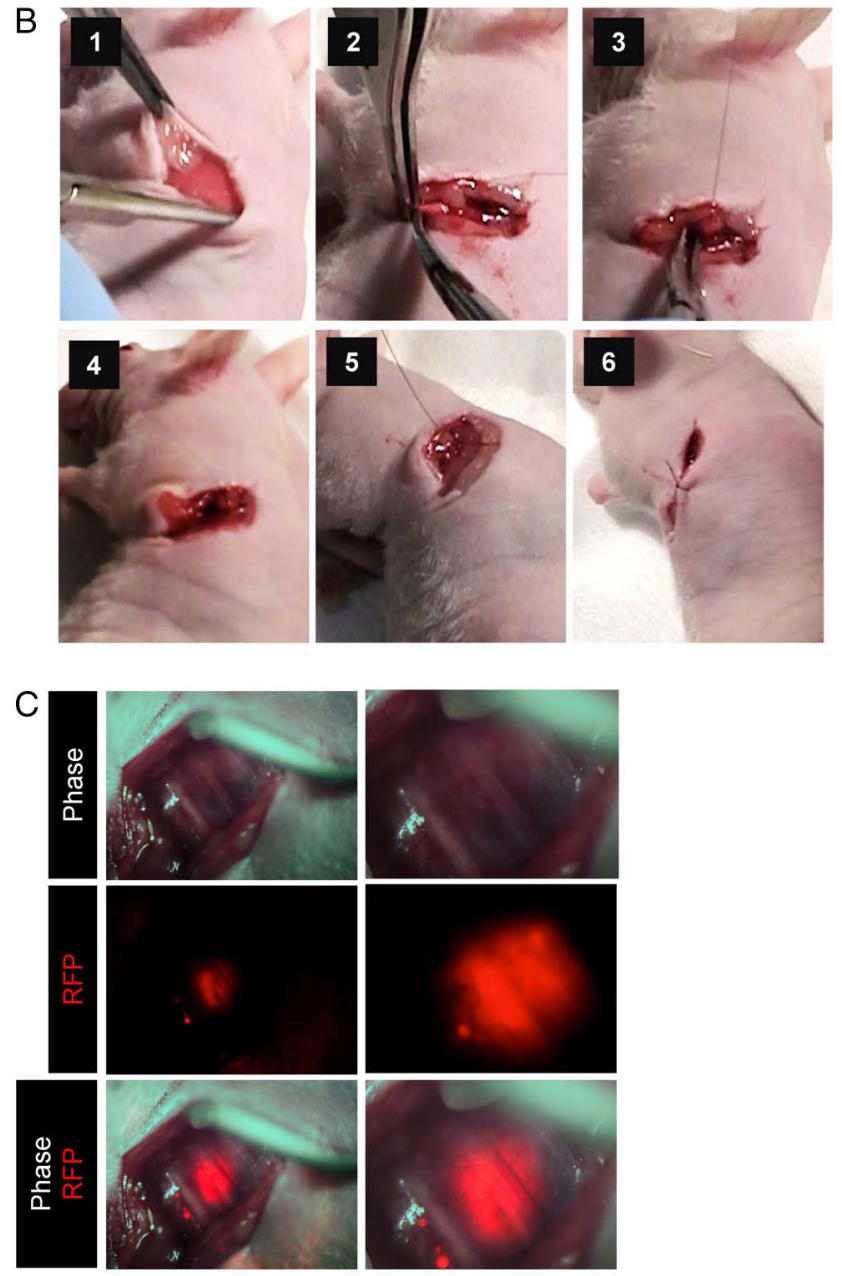

Figure 2 Orthotopic lung cancer mouse model. To obtain tumour stock for orthotopic transplantation, RFP-expressing A549 cells $\left(5 \times 10^{6}\right)$ were suspended in Matrigel and inoculated into the right flank of 5 -week-old female athymic nude mice. After tumour growth and harvest, the tumour tissue was cut into small pieces (diameter; 2-3 mm). A tumour fragment was sutured on the exposed lung with 8-0 nylon sutures.

(A) RFP-expressing tumour fragments produced from a subcutaneous tumour from RFP-expressing A549 human lung cancer cells (left panels, low magnification; right panels, high magnification). (B) Surgical orthotopic implantation of tumour fragments on the exposed lung in the thoracic cavity.

(1) Thoracotomy operation. (2) Isolation of the lower lobe of left lung. (3 and 4) Implantation of tumour fragments with 8-0 sutures. (5) Closure of chest wall with 6.0 sutures. (6) Closure of skin with 6.0 sutures. (C) Intravital imaging of A549-RFP lung cancer (OV100) (left panels, low magnification; right panels, high magnification). 

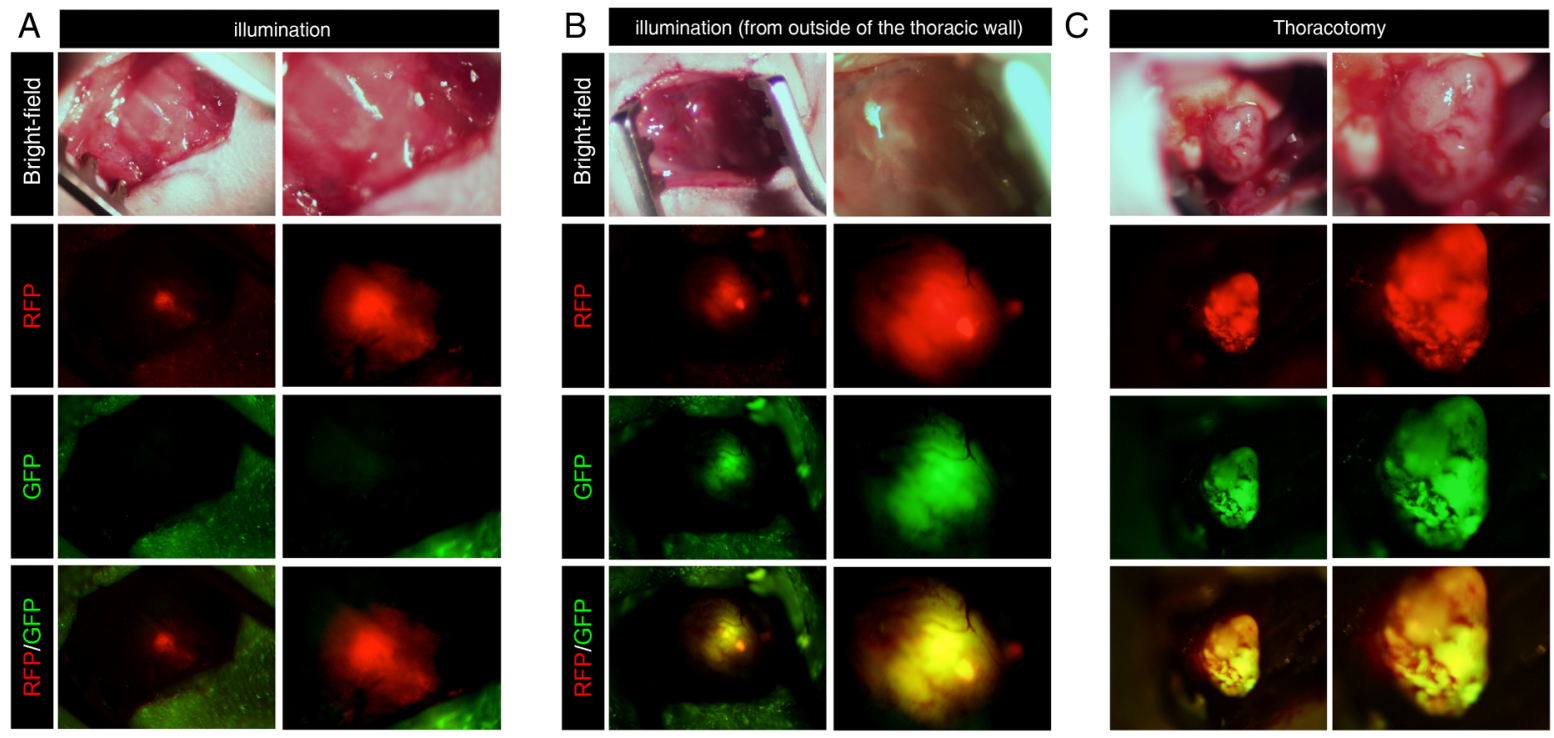

Figure 3 OBP-401 precisely labels orthotopic lung cancer. (A) Intravital imaging through the chest wall of A549-RFP lung tumour. (B) Intravital imaging through the chest wall of OBP-401-GFP labelling of A549-RFP tumour by OBP-401 injection through the chest wall. (C) Intravital imaging of OBP-401-GFP labelled A549-RFP lung tumour after thoracotomy. Images were acquired with the OV100. For A, B and C, left panels are low magnification; right panels are high magnification.

(figure 1A, C). GFP labelling of lung cancer cells with OBP-401 was visualised at the single cell level by confocal imaging (figure $1 \mathrm{~B}, \mathrm{D}$ ). These results indicated that OBP-401 labelled almost all cancer cells within 3 days after infection and suggested that OBP-401 FGS should be performed 2 or 3 days after infection with OBP-401.

To obtain a proper model for FGS of tumours in the lung, we implanted RFP-expressing tumour fragments, generated from harvested subcutaneous tumours, on the lungs of nude mice using surgical orthotopic implantation (figure 2A, B). ${ }^{16} 25$ We readily detected RFP-expressing tumours on the lungs external to the thorax by fluorescence imaging 1 week after implantation (figure 2C, see online supplementary movie S1).

OBP-401 was injected into the lung tumours by RFP guidance through the thoracic wall (figure $3 \mathrm{~A}$, see online supplementary figure S3). A549-RFP and H460-RFP cells,
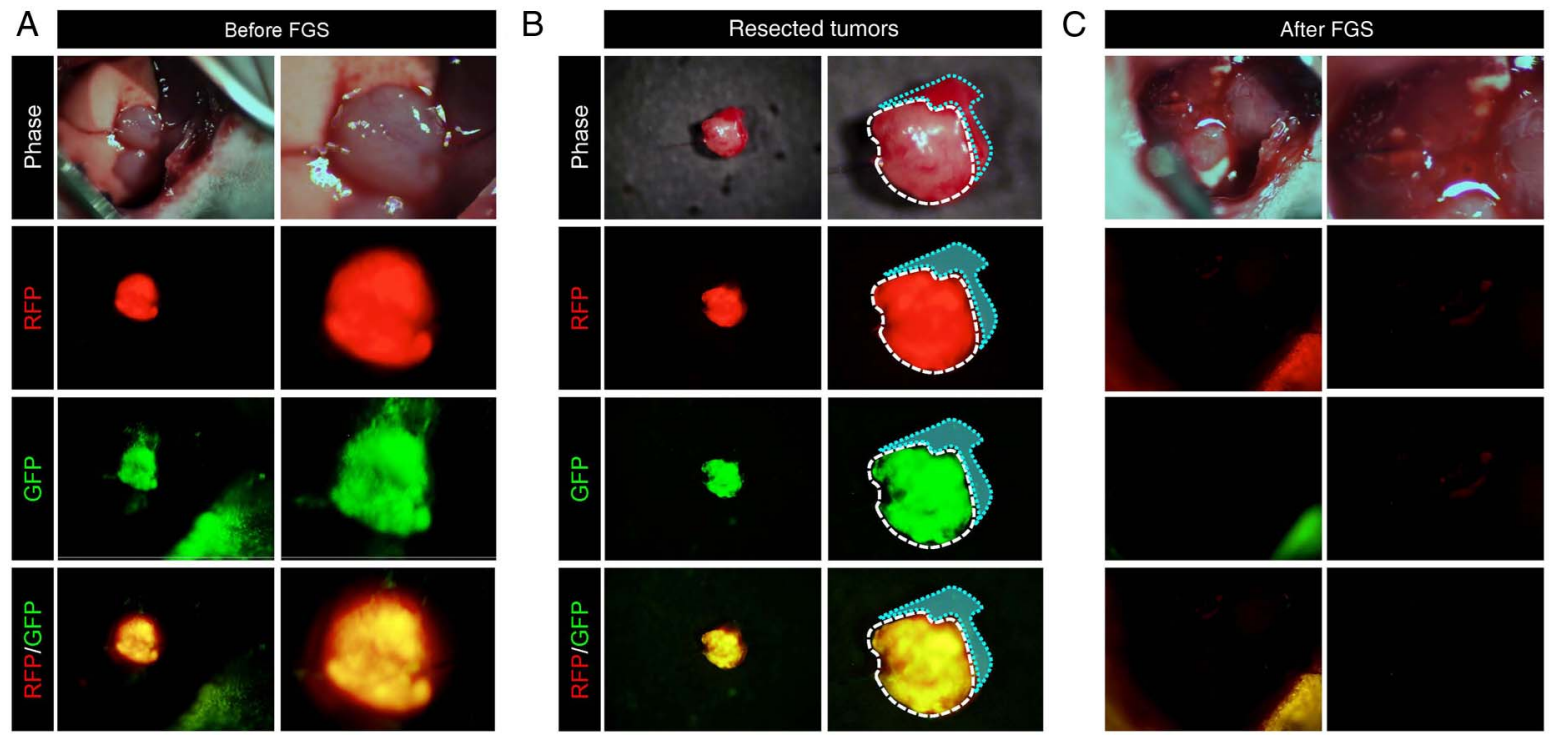

Figure 4 OBP-401-based fluorescence-guided surgery of orthotopic lung cancer. (A) Intravital imaging of OBP-401 labelling of A549-RFP lung tumour in situ with GFP. (B) Tumors resected by fluorescence-guided surgery of orthotopic A549-RFP lung cancer labelled with OBP-401 GFP and RFP. Dotted lines show the outline of the tumor border. (C) Representative images after fluorescence-guided surgery. Images were acquired with the OV100 (Olympus). For A, B and C, left panels are low magnification and right panels are high magnification. 
growing on the lung, expressed GFP 3 days after injection of OBP-401 (figure 3B and online supplementary figure S4, movie S2), respectively. Next, we performed intravital real-time imaging of A549-RFP and H460-RFP tumours with OBP-401-GFP on the lung after thoractomy (figure 3C and supplementary figure S3, respectively).

The thorax of mice was opened in order to intravitally image the tumour in the lung with assisted ventilation of the mice. ${ }^{29}$ We readily detected GFP labelling of A549 and $\mathrm{H} 460$ and identified the precise location of the tumours (figure 3C and online supplementary figure S4, movie S3, respectively). In contrast, the normal lung was not labelled by OBP-401 (see online supplementary figure S6).

The lung tumours were then resected under fluorescence guidance (figure 4, see online supplementary figure S5). The resected tumours co-expressed GFP and RFP (figure 4B, see online supplementary figure S5, movie S4). OBP-401-based FGS enabled complete resection of lung cancer (figure 4C).

\section{DISCUSSION}

FGS of the lung can be used alone or in combination with CT-based image guidance. The simplicity and high resolution of FGS has important potential for curative surgery. Tumours can be readily labelled with GFP using OBP-401. Other labelling techniques can be used, such as with fluorescent antibodies, if tumour-specific markers can be identified. OBP-401 has broad potential since most cancers express telomerase.

A phase I clinical trial of intratumoral injection of OBP-301, which is the parent of OBP-401, in patients with advanced solid tumours demonstrated that OBP-301 monotherapy was well tolerated by the patients, ${ }^{30}$ suggesting the clinical safety and potential of OBP-401-based FGS. A phase I trial of OBP-401-based FGS will be the subject of a future study.

Until it is possible to use OBP-401 in the clinic for FGS, animal studies will be the limit to the FGS strategy described above. Other means of labelling the lung tumours with fluorescent dyes ${ }^{31}$ can be used. The two methods can also be compared and contrasted to determine an optimal technology for FGS of lung cancer to begin clinical trials.

\section{Dedication This paper is dedicated in the memory of AR Moossa, MD.}

Contributors SY and RMH were involved in the conception and design of the study. SY and SM were involved in the development of methodology. SY and SM were involved in the acquisition of data (provided animals, provided facilities, etc). SY, SM and HK were involved in the analysis and interpretation of data (eg, statistical analysis, biostatistics, computational analysis). SY, TF and $\mathrm{RMH}$ were involved in the writing, review and/or revision of the manuscript. HK, TF and YU were involved in the administrative, technical or material support. HK, SK and TF were involved in the study supervision.

Funding This study was supported by grants-in-Aid from the Ministry of Education, Science and Culture, Japan and grants from the Ministry of Health and Welfare, Japan and by the U.S. National Cancer Institute grant CA142669.
Competing interests YU is President and CEO of Oncolys BioPharma, Inc., the manufacturer of OBP-401 (Telomescan). H Tazawa and TF are consultants of Oncolys BioPharma, Inc.

Provenance and peer review Not commissioned; externally peer reviewed.

Data sharing statement No additional data are available.

Open Access This is an Open Access article distributed in accordance with the Creative Commons Attribution Non Commercial (CC BY-NC 4.0) license, which permits others to distribute, remix, adapt, build upon this work noncommercially, and license their derivative works on different terms, provided the original work is properly cited and the use is non-commercial. See: http:// creativecommons.org/licenses/by-nc/4.0/

\section{REFERENCES}

1. McElroy M, Kaushal S, Luiken G, et al. Imaging of primary and metastatic pancreatic cancer using a fluorophore-conjugated anti-CA19-9 antibody for surgical navigation. World J Surg 2008;32:1057-66.

2. Kaushal S, McElroy MK, Luiken GA, et al. Fluorophore-conjugated anti-CEA antibody for the intraoperative imaging of pancreatic and colorectal cancer. J Gastrointest Surg 2008;12:1938-50.

3. Metildi CA, Kaushal S, Lee C, et al. An LED light source and novel fluorophore combinations improve fluorescence laparoscopic detection of metastatic pancreatic cancer in orthotopic mouse models. J Am Coll Surg 2012;214:997-1007.

4. Metildi CA, Kaushal S, Hardamon CR, et al. Fluorescence-guided surgery allows for more complete resection of pancreatic cancer, resulting in longer disease-free survival compared with standard surgery in orthotopic mouse models. J Am Coll Surg 2012;215:126-36.

5. Metildi CA, Kaushal S, Snyder CS, et al. Fluorescence-guided surgery of human colon cancer increases complete resection resulting in cures in an orthotopic nude mouse model. J Surg Res 2013;179:87-93.

6. Metildi CA, Tang CM, Kaushal S, et al. In vivo fluorescence imaging of gastrointestinal stromal tumors using fluorophoreconjugated anti-KIT antibody. Ann Surg Oncol 2013;20(Suppl 3): S693-700.

7. Metildi CA, Kaushal S, Pu M, et al. Fluorescence-guided surgery with a fluorophore-conjugated antibody to carcinoembryonic antigen (CEA), that highlights the tumor, improves surgical resection and increases survival in orthotopic mouse models of human pancreatic cancer. Ann Surg Oncol 2014;21:1405-11.

8. Metildi CA, Kaushal S, Luiken GA, et al. Fluorescently-labeled chimeric anti-CEA antibody improves detection and resection of human colon cancer in a patient-derived orthotopic xenograft (PDOX) nude mouse model. J Surg Oncol 2014;109:451-8.

9. Metildi CA, Kaushal S, Luiken GA, et al. Advantages of fluorescence-guided laparoscopic surgery of pancreatic cancer labeled with fluorescent anti-carcinoembryonic antigen antibodies in an orthotopic mouse model. J Am Coll Surg 2014;219:132-41.

10. Kishimoto $\mathrm{H}$, Zhao $\mathrm{M}$, Hayashi $\mathrm{K}$, et al. In vivo internal tumor illumination by telomerase-dependent adenoviral GFP for precise surgical navigation. Proc Natl Acad Sci USA 2009;106:14514-17.

11. Kishimoto $\mathrm{H}$, Urata $\mathrm{Y}$, Tanaka N, et al. Selective metastatic tumor labeling with green fluorescent protein and killing by systemic administration of telomerase-dependent adenoviruses. Mol Cancer Ther 2009;8:3001-8.

12. Kishimoto $H$, Aki $R$, Urata $Y$, et al. Tumor-selective adenoviral-mediated GFP genetic labeling of human cancer in the live mouse reports future recurrence after resection. Cell Cycle 2011;10:2737-41.

13. Yano S, Hiroshima $Y$, Maawy A, et al. Color-coding cancer and stromal cells with genetic reporters in a patient-derived orthotopic xenograft (PDOX) model of pancreatic cancer enhances fluorescence-guided surgery. Cancer Gene Ther 2015;22:344-50.

14. Yano S, Miwa S, Kishimoto $\mathrm{H}$, et al. Experimental curative fluorescence-guided surgery of highly invasive glioblastoma multiforme selectively labeled with a killer-reporter adenovirus. Mol Ther 2015;23:1182-8.

15. Yano S, Miwa S, Kishimoto $\mathrm{H}$, et al. Targeting tumors with a killer-reporter adenovirus for curative fluorescence-guided surgery of soft-tissue sarcoma. Oncotarget 2015;6:13133-48.

16. Wang $X, F u X$, Hoffman RM. A new patient-like metastatic model of human lung cancer constructed orthotopically with intact tissue via thoracotomy in immunodeficient mice. Int J Cancer 1992;51:992-5.

17. Goldstraw P, Ball D, Jett JR, et al. Non-small-cell lung cancer. Lancet 2011;378:1727-40. 
18. Farjah F, Backhus LM, Varghese TK, et al. Ninety-day costs of video-assisted thoracic surgery versus open lobectomy for lung cancer. Ann Thorac Surg 2014;98:191-6.

19. Hirschburger M, Sauer S, Schwandner T, et al. Extratumoral spiral fixed wire marking of small nodules for thoracoscopic resection. Thorac Cardiovasc Surg 2008;56:106-9.

20. Eichfeld U, Dietrich A, Ott R, et al. Video-assisted thoracoscopic surgery for pulmonary nodules after computed-tomography guided marker with a spiral wire. Ann Thorac Surg 2005;79:313-16.

21. Partil BL, Leung AN, Müller MR, et al. Using a dedicated lung-marker system for localization of pulmonary nodules before thoracoscopic surgery. Am J Roentgenol 2003;180:805-9.

22. Lizza N, Eucher P, Haxhe JP, et al. Thoracoscopic resection of pulmonary nodules after computed-tomography guided coil labeling. Ann Thorac Surg 2001;71:986-8.

23. Gobardhan PD, Djamin RS, Romme PJ, et al. The use of iodine seed (I-125) as a marker for the localization of lung nodules in minimal invasive pulmonary surgery. Eur J Surg Oncol 2013;39:945-50.

24. Kishimoto $\mathrm{H}$, Kojima $\mathrm{T}$, Watanabe $\mathrm{Y}$, et al. In vivo imaging of lymph node metastasis with telomerase-specific replication-selective adenovirus. Nat Med 2006;12:1213-19.
25. Wang $X, F u X$, Hoffman RM. A patient-like metastasizing model of human lung adenocarcinoma constructed via thoracotomy in nude mice. Anticancer Res 1992;12:1399-402.

26. Wang $\mathrm{X}, \mathrm{Fu} \mathrm{X}$, Kubota $\mathrm{T}$, et al. A new patient-like metastatic mode of human small-cell lung cancer constructed orthotopically with intact tissue via thoracotomy in nude mice. Anticancer Res 1992;12:1403-6.

27. Uchugonova A, Duong J, Zhang N, et al. The bulge area is the origin of nestin-expressing pluripotent stem cells of the hair follicle. J Cell Biochem 2011;112:2046-50.

28. Yamauchi K, Yang M, Jiang P, et al. Development of real-time subcellular dynamic multicolor imaging of cancer-cell trafficking in live mice with a variable-magnification whole-mouse imaging system. Cancer Res 2006;66:4208-14.

29. Kimura H, Hayashi K, Yamauchi K, et al. Real-time imaging of single cancer-cell dynamics of lung metastasis. $J$ Cell Biochem 2010;109:58-64.

30. Nemunaitis J, Tong AW, Nemunaitis M, et al. A phase I study of telomerase-specific replication competent oncolytic adenovirus (telomelysin) for various solid tumors. Mol Ther 2010;18:429-34.

31. Bouvet M, Hoffman RM. Glowing tumors make for better detection and resection. Sci Transl Med 2011;3:110fs10. 